\title{
Testicular Microlithiasis: Another Starry Sky Appearance
}

\author{
Adedayo A. Onitilo, MD, MSCR, FACP
}

\section{A} 36-year-old man presented with swelling of his right testicle that had been present for 3 weeks. Ultrasound of the left testicle showed diffuse microlithiasis throughout the testicular parenchyma, giving the appearance of a "starry sky." Histopathology of the left testicle after surgical removal revealed innumerable microcalcifications of the parenchyma, confirming the ultrasound findings (figure 1). The right testicle showed similar ultrasound and histopathologic findings as the left testicle (figure 2). Color Doppler studies showed a marked increase in the vascularity of the testicular parenchyma (figure 3). Thus, the
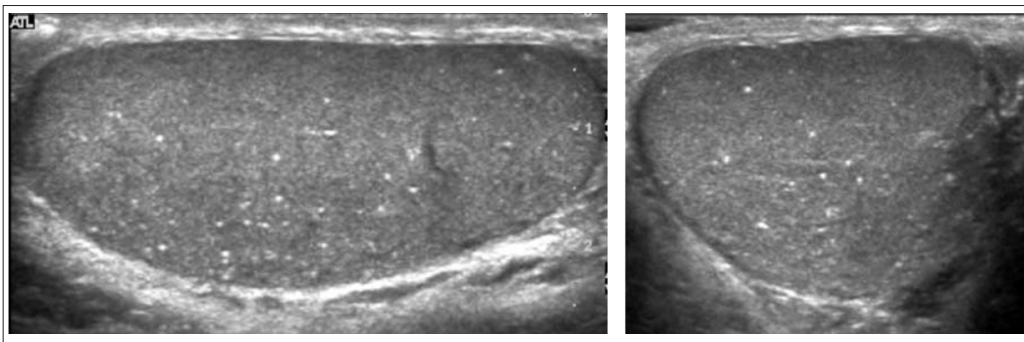

Figure 1. Left (contralateral) testicle showing "starry sky" appearance due to microlithiasis on ultrasound. Sagittal and transverse sections of patient's left testis reveal innumerable microcalcifications of the testicular parenchyma. diagnosis of testicular microlithiasis (TM) was made with a high degree of certainty, leading to a review of the literature on this entity.

$\mathrm{TM}$ is a relatively rare condition identified in approximately $0.6 \%$ of testicular ultrasonograms. ${ }^{1,2} \mathrm{TM}$ can be divided into
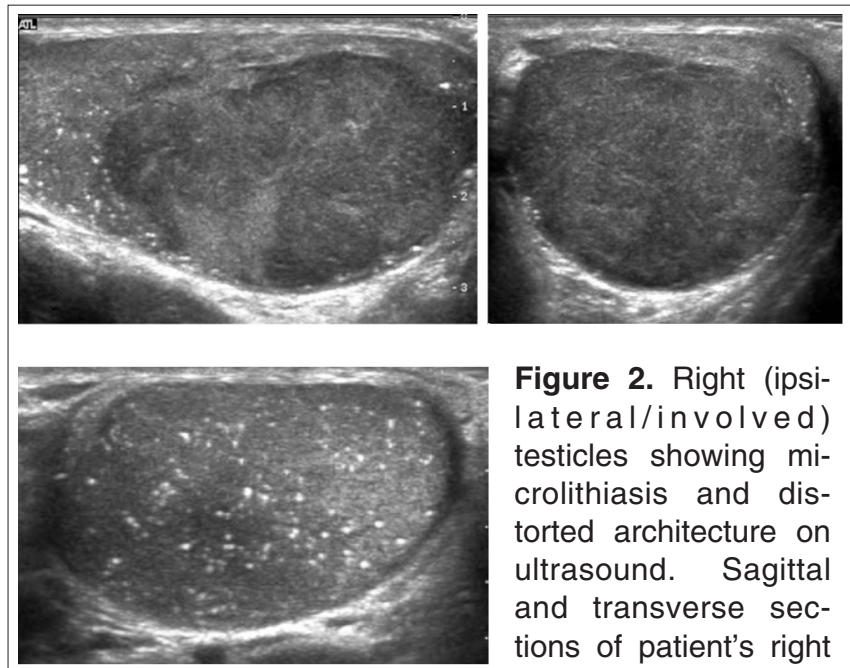

Figure 2. Right (ipsilateral/involved) testicles showing microlithiasis and distorted architecture on ultrasound. Sagittal and transverse sections of patient's right testis reveal innumerable microcalcifications of the testicular parenchyma. classic and limited on the basis of the presence of five or more microliths on one or more images of the testes. ${ }^{2}$ Classic TM is present if there is at least one ultrasound image that identifies five or more microliths in either or both testes. Patients who do not meet the criteria for chronic TM, but have at least one microlith are considered to have limited TM. ${ }^{2}$

TM has been associated in both benign and malignant conditions such as Klinefelter syndrome, ${ }^{3}$ male pseudohermaphroditism, ${ }^{4}$ Down syndrome, ${ }^{5}$ subfertility, ${ }^{6}$ infertility, ${ }^{7}$ cryptorchism, ${ }^{8}$ hypogonadism, ${ }^{3}$ fragile $\mathrm{X}$ syndrome, ${ }^{9}$ pseudoxanthoma elasticum, ${ }^{10}$ and pulmonary microlithiasis. ${ }^{11}$ Many of these benign conditions are risk factors for testicular malignancies. There are several reports of an association of TM with testicular cancer, with as many as $30 \%$ to $75 \%$ of patients with testicular tumors presenting with a concomitant TM.2,4,7,8,12-14 The relative risk of testicular tumors in the setting of TM is $>20$-fold, mandating sonographic surveillance for tumor. ${ }^{14}$ Thus, TM is believed by some authors to be a predisposing factor, a possible indirect indicator of premalignant disease or a tumor marker.

Although there is a scarcity of prospective studies on the risk of cancer developing in individuals with asymptomatic TM without other masses, tumor development during follow-up of
Reprint Requests: Adedayo A. Onitilo, MD, MSCR, FACP

Marshfield Clinic Weston Center

Department of Hematology/Oncology

350 I Cranberry Boulevard

Weston, WI 5440

Tel: 7I5-393-1400; Fax: 7| 5-393-1399

Email: onitilo.adedayo@marshfieldclinic.org
Keywords: Microcalcification; Testicular cancer; Ultrasound;

Testicular microlithiasis

Received: March 6, 2007

Accepted: March 23, 2007

doi: $10.3121 / \mathrm{cmr} .2007 .760$

The Aperture, like the opening in the lens of a microscope that allows light to pass through, is a forum for art, humor, and images that provides a portal for new or different views of medicine and research. 

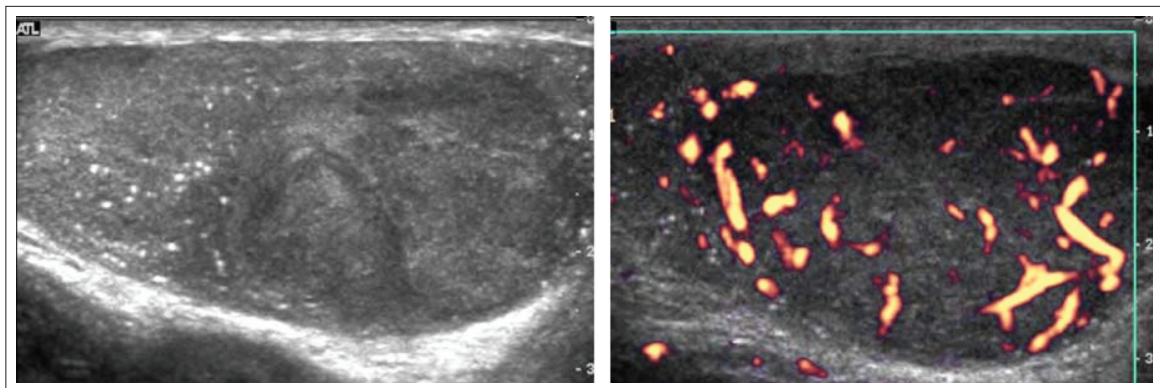

Figure 3. Markedly increased vascularity of the patient's testicular structures evident upon examination by color Doppler.

TM has been described to have a latency period between 15 months and 11 years. ${ }^{4}$ If no malignancy is identified on initial evaluation, close clinical follow-up with periodic (every 6 to 12 months) scrotal ultrasound examination is probably indicated. In high risk patients or patients with contralateral tumors, tumor markers and biopsy may also be indicated based on clinical suspicion. Thus, microlithiases are believed to be a predisposing factor, a possible indirect indicator of premalignant disease, or a tumor marker.

\section{References}

1. Hobarth K, Susani M, Szabo N, Kratzik C. Incidence of testicular microlithiasis. Urology 1992;40:464-467.

2. Middleton WD, Teefey SA, Santillan CS. Testicular microlithiasis: prospective analysis of prevalence and associated tumor. Radiology 2002;224:425-428.

3. Aizenstein RI, Hibbeln JF, Sagireddy B, Wilbur AC, O’Neil HK. Klinefelter's syndrome associated with testicular microlithiasis and mediastinal germ-cell neoplasm. J Clin Ultrasound 1997;25:508-510.

4. Guzman Martinez-Valls PL, Hita Villaplana G, Fernandez Aparicio T, Minana Lopez B, Martinez Diaz F, Sanchez Gascon F. [Significance and management of testicular microlithiasis]. Arch Esp Urol 2003;56:472-477.

5. Vachon L, Fareau GE, Wilson MG, Chan LS. Testicular microlithiasis in patients with Down syndrome. J Pediatr 2006; 149:233-236.

6. de Gouveia Brazao CA, Pierik FH, Oosterhuis JW, Dohle GR, Looijenga LH, Weber RF. Bilateral testicular microlithiasis predicts the presence of the precursor of testicular germ cell tumors in subfertile men. J Urol 2004;171:158-160.

7. Sakamoto H, Shichizyou T, Saito K, Okumura T, Ogawa Y, Yoshida H, Kushima M. Testicular microlithiasis identified ultrasonographically in Japanese adult patients: prevalence and associated conditions. Urology 2006;68:636-641.

8. Konstantinos S, Alevizos A, Anargiros M, Constantinos M, Athanase H, Konstantinos B, Michail E, Fragiskos S. Association between testicular microlithiasis, testicular cancer, cryptorchidism and history of ascending testis. Int Braz J Urol 2006;32:434-438.

9. Pourbagher MA, Pourbagher A, Erol I. Fragile X syndrome associated with testicular microlithiasis in siblings. J Ultrasound Med 2005;24:1727-1729.

10. Bercovitch RS, Januario JA, Terry SF, Boekelheide K, Podis AD, Dupuy DE, Bercovitch LG. Testicular microlithiasis in association with pseudoxanthoma elasticum. Radiology 2005;237:550-554.

11. Arslan A, Yalin T, Akan H, Belet U. Pulmonary alveolar microlithiasis associated with calcifications in the seminal vesicles. J Belge Radiol 1996;79:118-119.
12. Bach AM, Hann LE, Shi W, Giess CS, Yoo HH, Sheinfeld J, Thaler HT. Is there an increased incidence of contralateral testicular cancer in patients with intratesticular microlithiasis? AJR Am J Roentgenol 2003;180:497-500.

13. Backus ML, Mack LA, Middleton WD, King BF, Winter TC 3rd, True LD. Testicular microlithiasis: imaging appearances and pathologic correlation. Radiology 1994;192:781-785.

14. Cast JE, Nelson WM, Early AS, Biyani S, Cooksey G, Warnock NG, Breen DJ. Testicular microlithiasis: prevalence and tumor risk in a population referred for scrotal sonography. AJR Am J Roentgenol 2000;175:1703-1706.

\section{Author Affiliation \\ Adedayo A. Onitilo, MD, MSCR, FACP \\ Department of Hematology/Oncology \\ Marshfield Clinic Weston Center \\ Weston, Wisconsin}

